\title{
HAZ MICROFISSURING IN EB WELDED ALLVAC 718 PLUS ${ }^{\mathrm{TM}}$ ALLOY
}

\author{
K.R. Vishwakarma, N.L. Richards and M.C. Chaturvedi \\ Department of Mechanical and Manufacturing Engineering, University of Manitoba, \\ Winnipeg, Manitoba, Canada R3T 5V6
}

Keywords: weldability, liquation microfissuring, microstructures, total crack length

\begin{abstract}
Weldability of two versions of newly developed 718 Plus alloy, HC49 and HC20 was studied and compared with that of Inconel 718. 5.0" x $0.5 " \times 0.5$ " thick plates were heat treated at $950^{\circ}$ and $1050^{\circ} \mathrm{C}$, water-quenched then EB welded. Microstructures of the base metal and welds were examined by optical and analytical electron microscopy. Intergranular microcracks were observed in HAZ in all the three alloys, and their susceptibility to cracking was established by measuring total and maximum crack lengths. It was observed that $\mathrm{HC} 49$, with higher $\mathrm{B}$ and $\mathrm{P}$, suffered most cracking and Inconel 718 the least. HAZ cracking was observed to be associated with resolidified liquated phase suggesting it to be liquation cracking. The EDS analysis suggested that the grain boundary liquation was due to the constitutional liquation of $\mathrm{NbC}$ and due to the GB segregation of B during the pre-weld heat treatment. The increased cracking in 718 Plus as compared to Inconel 718 was attributed to the softer matrix of Inconel 718, which could withstand the welding stresses better. More severe cracking in higher B version of 718 Plus than in the lower B 718 Plus could be due to the increased segregation of B on its grain boundaries.
\end{abstract}

\section{Introduction}

High temperature components used in aero-engines and power generation turbines are made of superalloys due to their superior high temperature properties. Nevertheless, these components do suffer damage during service because of the extremely hostile environment in which they operate. Owing to their high cost, it is more economical to repair these service-damaged components, often by welding, than to replace them, however, repair welding of superalloys is frequently associated with various types of cracking. For example, superalloys, like Waspaloy and Inconel 718 suffer from microfissuring in the weld heat affected zone [1,2]. Although Inconel 718 has better weldability than that of Waspaloy, the latter has a higher operating temperature limit. Allvac 718 Plus $^{\mathrm{TM}}$ (referred to as 718 Plus) is a new superalloy which has been developed to have high temperature properties similar to that of Waspaloy and processing capabilities similar to that of Inconel 718. Its maximum operating temperature is $37.8^{\circ} \mathrm{C}\left(100^{\circ} \mathrm{F}\right)$ higher than that of the conventional Inconel 718 and its composition has been designed to have better creep properties as well. The development of this alloy has been discussed in detail elsewhere [3]. As stated earlier, Inconel 718 is considered to be a weldable alloy; however, it suffers from heat affected zone (HAZ) intergranular microfissuring. It is an iron base superalloy, strengthened by ordered $\mathrm{BCT} \gamma^{\prime \prime}\left(\mathrm{Ni}_{3} \mathrm{Nb}\right)$ precipitates. Its weldability and issues related to it have been studied both in wrought and cast conditions. Various reasons attributed to microfissuring in wrought Inconel 718 are constitutional liquation of MC type carbides [4], boron-carbides and $\delta$ phase assisted liquation cracking [5], and by the liquation of $B$ and other 
minor alloying elements like $\mathrm{C}, \mathrm{P}$ and $\mathrm{S}$ segregated grain boundaries [2, 6-10]. The major changes in the composition of 718 Plus alloy as compared to Inconel 718 are (1) increase in the concentration of $\mathrm{Al}, \mathrm{Ti}, \mathrm{B}, \mathrm{P}$ and $\mathrm{Co}$ and (2) a decrease in the Fe concentration. These changes have caused a significant change in the strengthening phase and its rate of precipitation, which are likely to have a significant effect on the welding characteristic of 718 Plus alloy. Therefore, a study was initiated to assess its weldability and compare it with that of Inconel 718.

\section{Experimental Methods and Materials}

Two versions of 718 Plus alloys, HC 20 with 60 ppm P and 30 ppm B and HC 49 with higher B $(50 \mathrm{ppm})$ and $\mathrm{P}(130 \mathrm{ppm})$ were studied along with the conventional Inconel 718 . The composition of the three alloys is given in Table 1 . Wrought plates of dimension 5" 1 " 0.5 " inch were pre-weld.

Table I. Chemistry of Alloys

\begin{tabular}{|l|c|c|c|}
\hline wt \% & Conventional Inconel 718 & Allvac 718 Plus HC 49 & Allvac 718 Plus HC 20 \\
\hline $\mathrm{Ni}$ & 54.44 & 52.21 & 52.18 \\
$\mathrm{Fe}$ & 17.62 & 9.66 & 9.33 \\
$\mathrm{Cr}$ & 17.94 & 17.42 & 17.92 \\
$\mathrm{Co}$ & 0.13 & 9.13 & 9.00 \\
$\mathrm{C}$ & 0.026 & 0.028 & 0.022 \\
$\mathrm{Nb}$ & 5.36 & 5.48 & 5.51 \\
$\mathrm{Ti}$ & 0.94 & 0.71 & 0.74 \\
$\mathrm{Al}$ & 0.46 & 1.46 & 1.50 \\
$\mathrm{~B}$ & 0.004 & 0.005 & 0.003 \\
$\mathrm{P}$ & 0.007 & 0.013 & 0.006 \\
$\mathrm{Mo}$ & 2.93 & 2.72 & 2.68 \\
$\mathrm{~W}$ & $<0.01$ & 1.04 & 1.04 \\
$\mathrm{~S}$ & $<0.0003$ & $<0.0003$ & $<0.0003$ \\
$\mathrm{Si}$ & 0.05 & 0.05 & 0.02 \\
$\mathrm{Mn}$ & 0.05 & 0.05 & 0.03 \\
$\mathrm{Mg}$ & 0.0014 & 0.0012 & 0.0008 \\
\hline
\end{tabular}

heat treated in argon at $950^{\circ} \mathrm{C}$ and $1050^{\circ} \mathrm{C}$ for one hour and then water quenched. The reasons for selection of these two temperatures were that (1) the commercial heat treatment of these two alloys is done at $950^{\circ} \mathrm{C}$, (2) the solvus of $\delta$ phase is around $1025^{\circ} \mathrm{C}$ and heat treatment at this temperature results essentially in a single phase material. Grain size and hardness of all the three alloys were measured in both the pre-weld solution treated conditions. Autogenous EB welds were made using $44 \mathrm{kV}$ voltage, $79 \mathrm{~mA}$ current and $152 \mathrm{~cm} / \mathrm{min}$ speed. The weldability was assessed by measuring the total crack length and maximum crack length in ten metallographic specimens of weld sections cut perpendicular to the welding directions. Metallographic specimens were prepared by standard polishing technique and etched either by modified Kalling's reagent or electrolytically in $10 \%$ oxalic acid. Microstructural examination was carried out with optical microscope and quantitative image analyzer, JEOL JSM-5900 LV scanning electron microscope (SEM) equipped with Oxford thin window EDS system. 


\section{Results}

Microstructure of Pre-Weld Heat Treated Alloys

The alloys were pre-weld heat treated at $950^{\circ} \mathrm{C}$ and $1050^{\circ} \mathrm{C}$ for 1 hour and water-quenched. The hardness and grain size of the solution treated alloys are given in Table II. It is seen that the hardness of Inconel 718 was significantly less than that of both the 718 Plus alloys. The grain size of all the three alloys was, however, almost the same. An increase in the pre-weld heat treatment temperature increased the grain size but the hardness decreased, although the hardness of 718 Plus alloys was still greater than that of Inconel 718.

Table II. Grain Size and Hardness Values of the Alloys Before and After Welding

\begin{tabular}{|c|c|c|c|c|}
\hline $\begin{array}{l}\text { Heat } \\
\text { Treatment }\end{array}$ & & $\begin{array}{c}\text { Conventional } \\
\text { IN } 718\end{array}$ & $\begin{array}{c}\text { Allvac } 718 \text { Plus } \\
\text { HC } 49\end{array}$ & $\begin{array}{c}\text { Allvac } 718 \text { Plus } \\
\text { HC } 20\end{array}$ \\
\hline \multirow{3}{*}{$\begin{array}{l}950^{\circ} \mathrm{C} / 1 \\
\mathrm{hr}+\text { water } \\
\text { quenching }\end{array}$} & Grain size $(\mu m)$ & $48 \pm 7$ & $42 \pm 7$ & $54 \pm 6$ \\
\hline & Base metal hardness & $223 \pm 4$ & $293 \pm 8$ & $295 \pm 7$ \\
\hline & Fusion zone hardness & $245 \pm 4$ & $257 \pm 6$ & $250 \pm 8$ \\
\hline \multirow{3}{*}{$\begin{array}{l}1050^{\circ} \mathrm{C} / 1 \\
\mathrm{hr}+\text { water } \\
\text { quenching }\end{array}$} & Grain size $(\mu m)$ & $100 \pm 14$ & $116 \pm 7$ & $73 \pm 8$ \\
\hline & Base metal hardness & $165 \pm 3$ & $201 \pm 10$ & $196 \pm 5$ \\
\hline & Fusion zone hardness & $241 \pm 5$ & $248 \pm 6$ & $248 \pm 6$ \\
\hline
\end{tabular}

Figs. 1a and $\mathrm{b}$ show secondary electron SEM images of $\mathrm{HC} 20$ alloy in the $950^{\circ} \mathrm{C}$ and $1050^{\circ} \mathrm{C}$ heat treated condition, respectively. It is seen that the $950^{\circ} \mathrm{C}$ treatment did not dissolve all the second phase particles. Needle shape particles, which were identified to be $\delta$-phase by EDS analysis, were observed at grain boundaries, and also occasionally on twin boundaries. In addition $\mathrm{Nb}$ rich $\mathrm{MC}$ carbides and $\mathrm{Ti}$ rich carbonitride particles were also observed. As seen in Fig. 1a, they were present within the grain as well as on the grain boundaries. The solution treatment at $1050^{\circ} \mathrm{C}$ dissolved the $\delta$-phase, Fig. $1 \mathrm{~b}$, but increased the grain size (Table II), although the increase in grain size of HC 20 alloy was less than that of the Inconel 718 and HC 49 alloy (Table II). Some $\mathrm{NbC}$ and $\mathrm{Ti}(\mathrm{CN})$ particles were, however, still present after the $1050^{\circ} \mathrm{C}$ heat treatment. Microstructures of the other two alloys were similar to that of the HC 20.
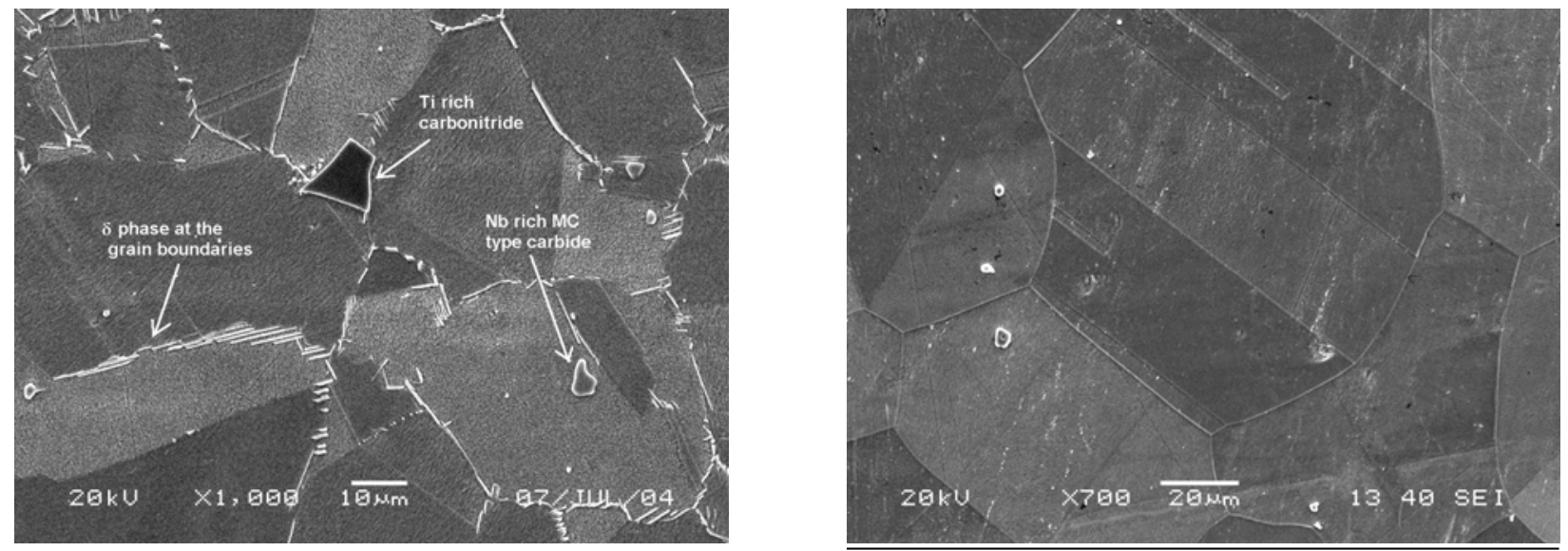

Fig. 1. Microstructure of HC 20718 Plus alloy after (a) $950^{\circ} \mathrm{C}$ and (b) $1050^{\circ} \mathrm{C}$ heat treatment. 
Autogenous EB welding was done on all the three alloys, in both the heat treated condition, by using welding parameters given in the previous section. As shown in Fig. 2, which is a low magnification, optical micrograph of a HC 20718 Plus alloy weld, the weld profile was that of a typical EB weld, i.e., nail-head shaped and intergranular microfissures were present mostly under the nail head and neck. The profile of welds and location of microcracks in all the three alloys was the same. Porosity was also observed at the other end of the nail-shape weld and occasionally intergranular micro-fissures associated with the porosity were also observed. Except for a few cracks that were observed associated with these porosities, no other cracks were ever observed in the weld- metal of any of the three alloys. Intergranular microfissures in HAZ were observed in all the three alloys. Total crack length of these microfissures was measured by examination of 10 metallographic sections, cut perpendicular to the welds, by using SEM and JEOL point-to-point measurement software. The total crack length of HAZ microfissures is given in Table III and histograms are illustrated in Fig. 3. It is seen that the values of total crack

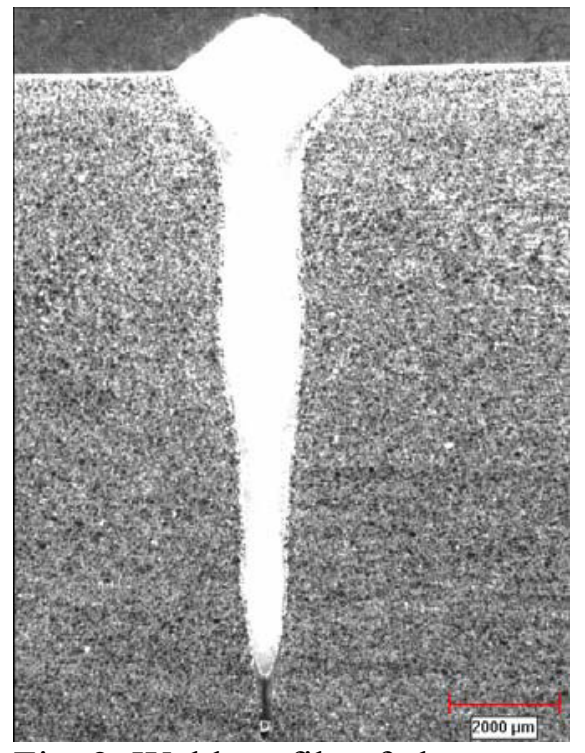

Fig. 2. Weld profile of electron beam welded HC 20718 Plus alloy.

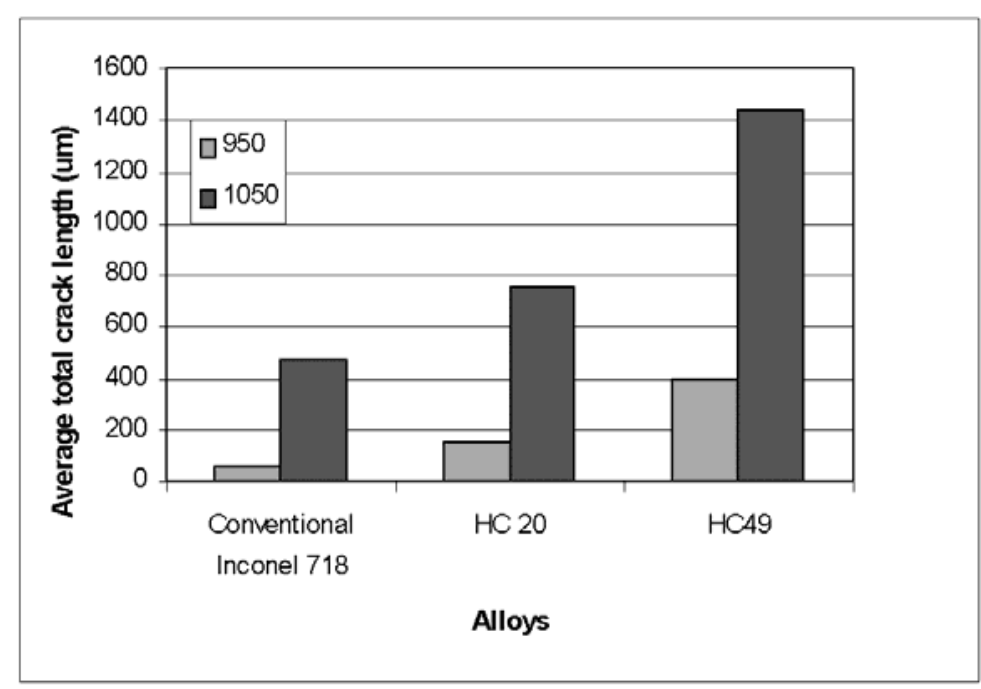

Fig. 3. Comparative cracking in Inconel 718 and 718 Plus Alloys in both the heat treatment conditions.

Table III. Microfissuring in the alloys in both the solutionizing heat treatments

\begin{tabular}{|l|c|c|c|c|}
\hline \multirow{2}{*}{ Alloys } & \multicolumn{2}{|c|}{$950^{\circ} \mathrm{C}$} & \multicolumn{2}{c|}{$1050^{\circ} \mathrm{C}$} \\
\cline { 2 - 5 } & $\begin{array}{c}\text { Average crack } \\
\text { length }(\mu \mathrm{m})\end{array}$ & $\begin{array}{c}\text { Maximum crack } \\
\text { length }(\mu \mathrm{m})\end{array}$ & $\begin{array}{c}\text { Average crack } \\
\text { length }(\mu \mathrm{m})\end{array}$ & $\begin{array}{c}\text { Maximum crack } \\
\text { length }(\mu \mathrm{m})\end{array}$ \\
\hline $\begin{array}{l}\text { Conventional } \\
\text { Inconel 718 }\end{array}$ & $588 \pm 36$ & 72 & $4027 \pm 88$ & 373 \\
\hline $\begin{array}{l}718 \text { type } \\
\text { HC 20 }\end{array}$ & $1028 \pm 56$ & 209 & $7503 \pm 964$ & 468 \\
\hline $\begin{array}{l}718 \text { type } \\
\text { HC 49 }\end{array}$ & $3993 \pm 55$ & 253 & $14394 \pm 69$ & 419 \\
\hline
\end{tabular}

length in the $950^{\circ} \mathrm{C}$ pre-weld heat treated condition was significantly less than the values observed in the $1050^{\circ} \mathrm{C}$ heat treated material. In addition, the extent of cracking was minimum in Inconel 718 as compared to that observed in 718 Plus alloy. However, it was significantly greater in the HC 49 version with higher B and $\mathrm{P}$ as compared to $\mathrm{HC} 20$ with normal $\mathrm{P}$ and $\mathrm{B}$ 
concentration and Inconel 718. The values of maximum crack length, which is also a criterion for evaluating weldability, was also significantly higher in both the 718 Plus alloys, and increased with an increase in B and P concentration (i.e. HC 49 vs. HC 20). Similarly, maximum crack lengths also increased with an increase in the pre-weld solution treatment temperature of the material. However, the difference in the maximum crack length between the three alloys was not as significant as was the difference in the total crack length. The effect of increase in grain size of the three alloys, due to an increase in the pre-weld heat treatment temperature, is shown in Fig. 4. As has been observed in earlier investigation [8], the increase in grain size due to increase in the heat treatment temperature resulted in an increase in total crack length in all the three alloys.

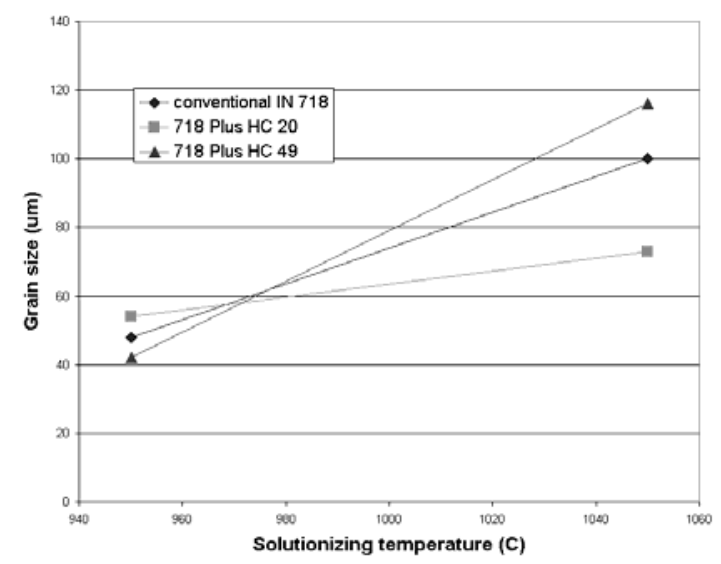

Fig. 4. Effect of grain size on the total crack length

\section{Microstructural Analysis of Welds}

Microstructure of the welds consisted of fusion zone, heat affected zone and the base metal. The fusion zone had a fine dendritic microstructure and a typical example is shown in Fig. 5. The inter-dendritic regions were found to be enriched with $\mathrm{Nb}$ and resulted in formation of Laves phase. Occasionally, $\mathrm{Ti}$ rich carbonitrides and $\mathrm{Nb}$ rich carbides were also seen randomly present in the fusion zone. In a few locations in the fusion zone Laves $+\gamma$ eutectic structure was also observed, which was seen to be associated with coarse MC type carbide particles, as shown in Fig. 6. Boron peaks were often observed on the energy dispersive x-ray spectra obtained from such coarse carbides, but boron could not be quantitatively analyzed due the limitation of the EDS analysis software. The average composition of various phases analyzed by EDS analysis is listed in Table IV.

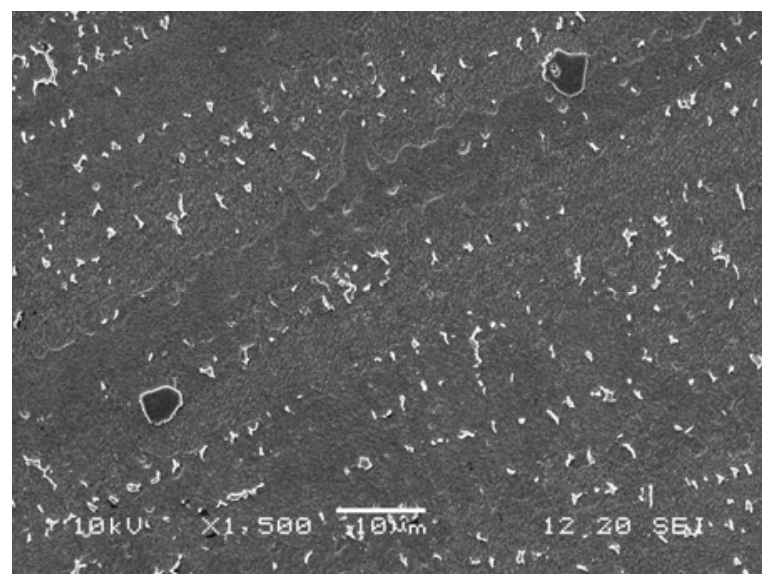

Fig. 5. Fusion zone of electron beam welded HC 20 alloy.

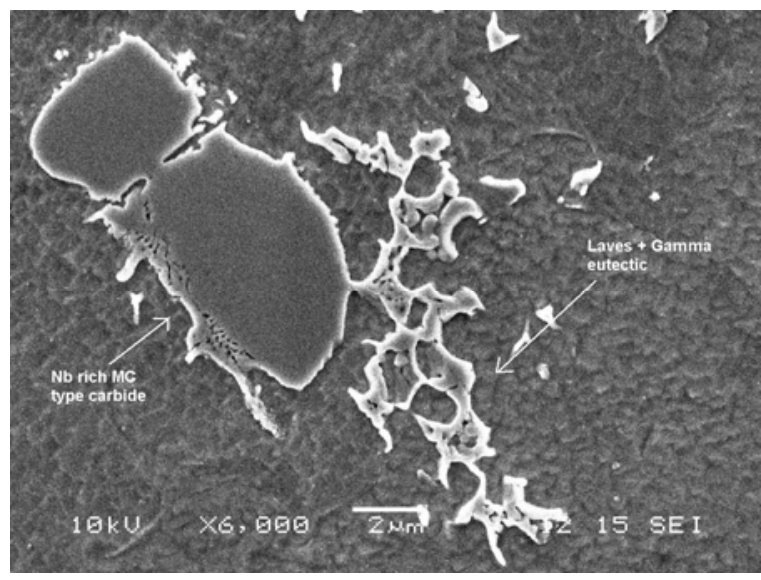

Fig. 6. MC type carbide with associated Laves $+\gamma$ eutectic in fusion zone of HC20 


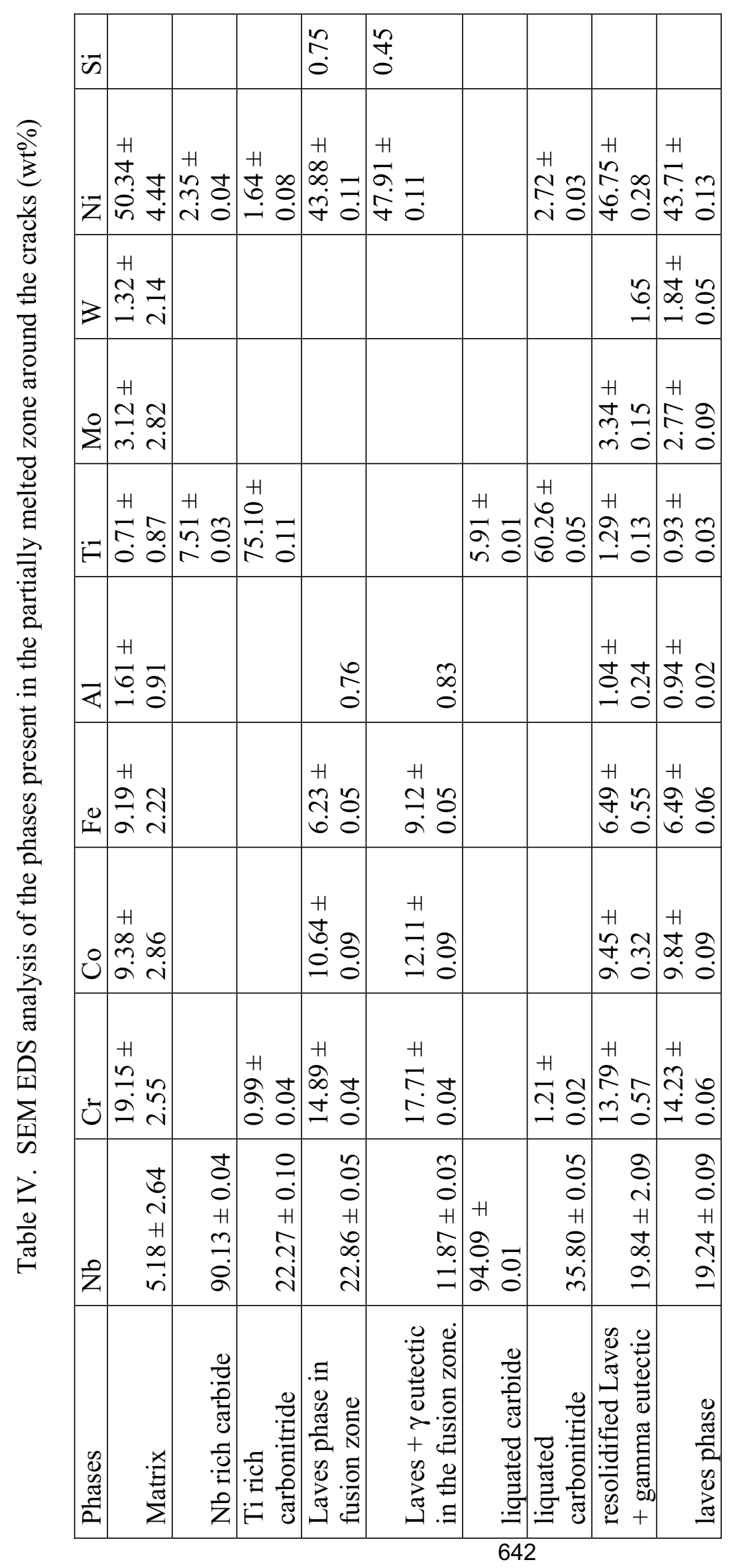


Fig. 7a and 7b, which are secondary electron SEM micrographs, show examples of HAZ microfissures in HC 20 and HC 49718 plus alloy, respectively. As seen in these micrographs, the micro-cracks in HAZ were intergranular and had associated with them liquated and resolidified products on grain boundaries. The cracks were often observed to be connected with the weld pool by a liquated grain boundary with a continuous string of precipitates on it. All the
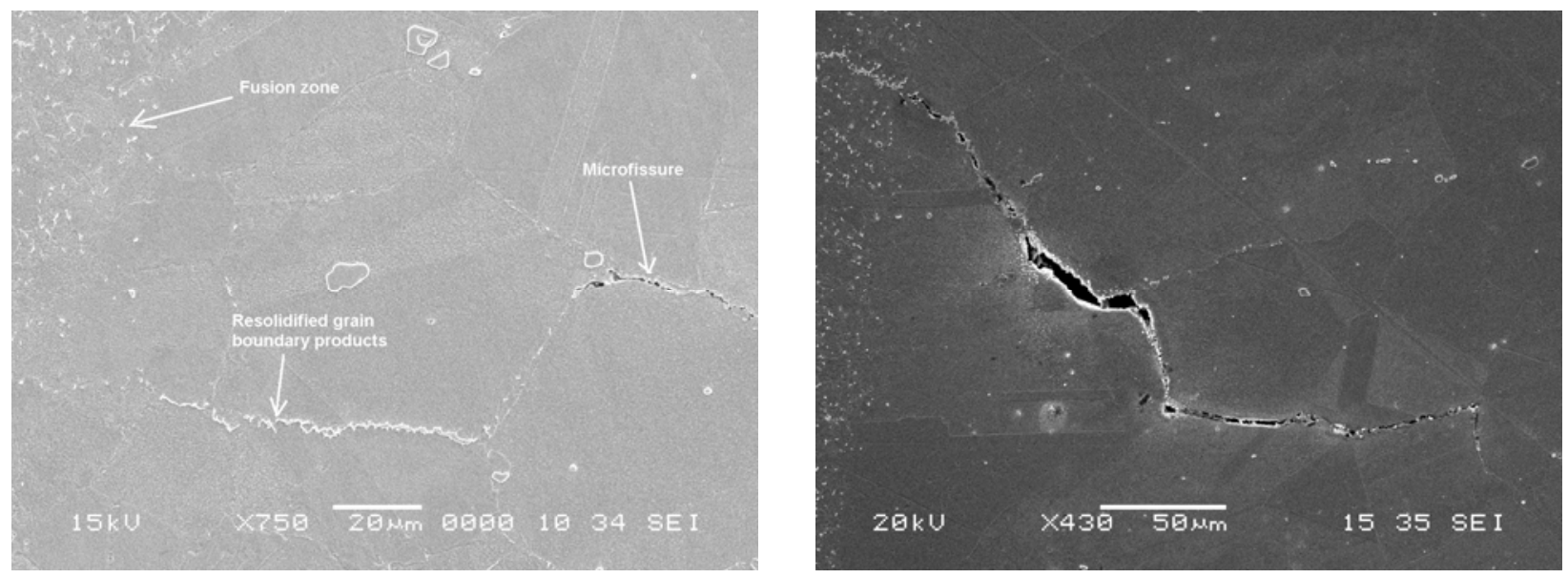

Fig. 7.Intergranular HAZ microcracking in (a)HC 20 and (b) in HC 49718 Plus alloys

liquated grain boundaries showed an enrichment by $\mathrm{Nb}$. The resolidified products were identified to be Laves $+\gamma$ eutectic and MC type carbide particles. Some Ti rich nitride particles on the grain boundaries were also observed to be liquated, and a few Laves particles were also seen to be present around the cracks. Fig. 8a, with a magnified micrograph of the marked area provided in Fig. 8b, shows the morphology of Laves $+\gamma$ eutectic that was observed on a microfissured grain boundary with re-solidified product on it. The average concentration of $\mathrm{Nb}$ in this product was determined to be $20 \mathrm{wt} \%$ by SEM EDS analysis. Similar re-solified products have been reported in the literature to be present in the liquated and re-solidified grain boundaries in the conventional Inconel 718 alloy welds [8-11].
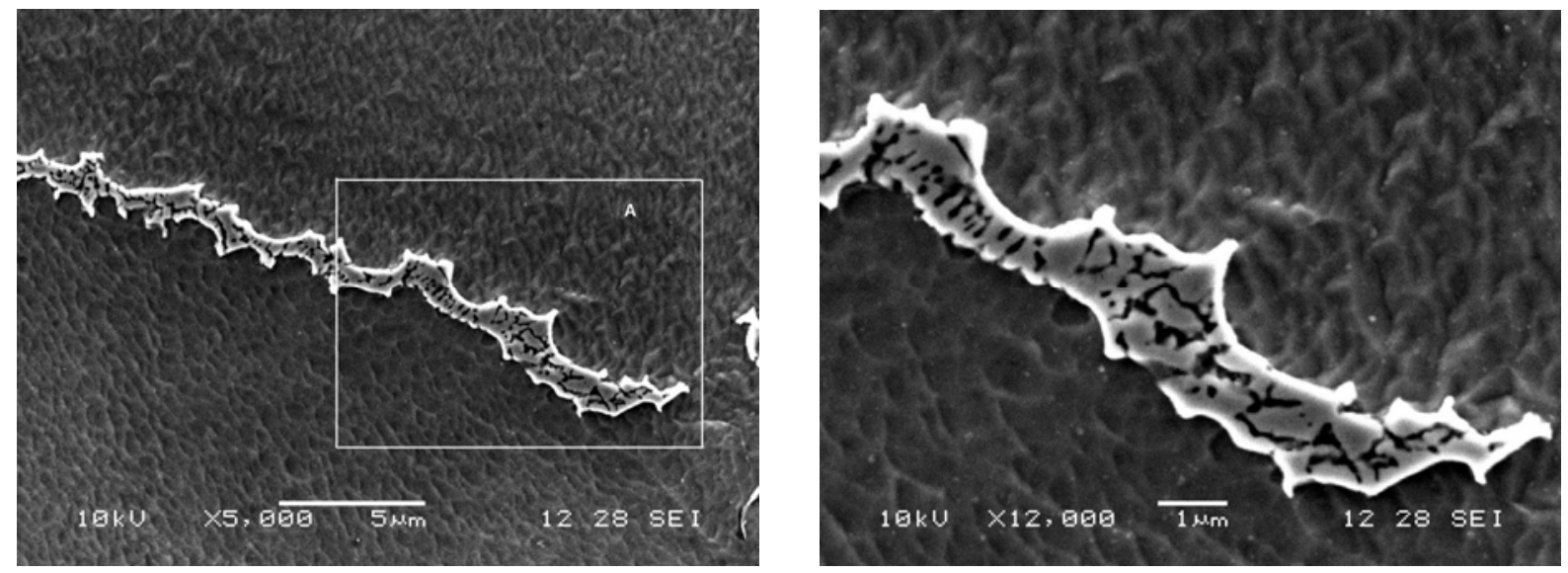

Fig. 8a. Laves $+\gamma$ eutectic at the melted grain boundary in the HAZ 8b. Magnified image of inset A in Figure 8a.

Liquated $\mathrm{Nb}$ rich $\mathrm{MC}$ type carbide and $\mathrm{Ti}$ rich carbo-nitride were also seen along liquated grain boundaries. Figures $9 \mathrm{a}$ and $10 \mathrm{a}$ show liquated $\mathrm{Nb}$ rich $\mathrm{MC}$ type carbide and Ti rich carbo-nitride, respectively, with their respective EDS spectra shown in Figs $9 \mathrm{~b}$ and $10 \mathrm{~b}$. The average composition of various phases determined by the SEM- EDS analysis is also listed in Table 4. Carbon and nitrogen peaks were observed in the EDS spectra of these phases, but again they 
could not be quantified due the inability of the EDS software to quantify light elements, hence they were excluded from the quantitative analysis.
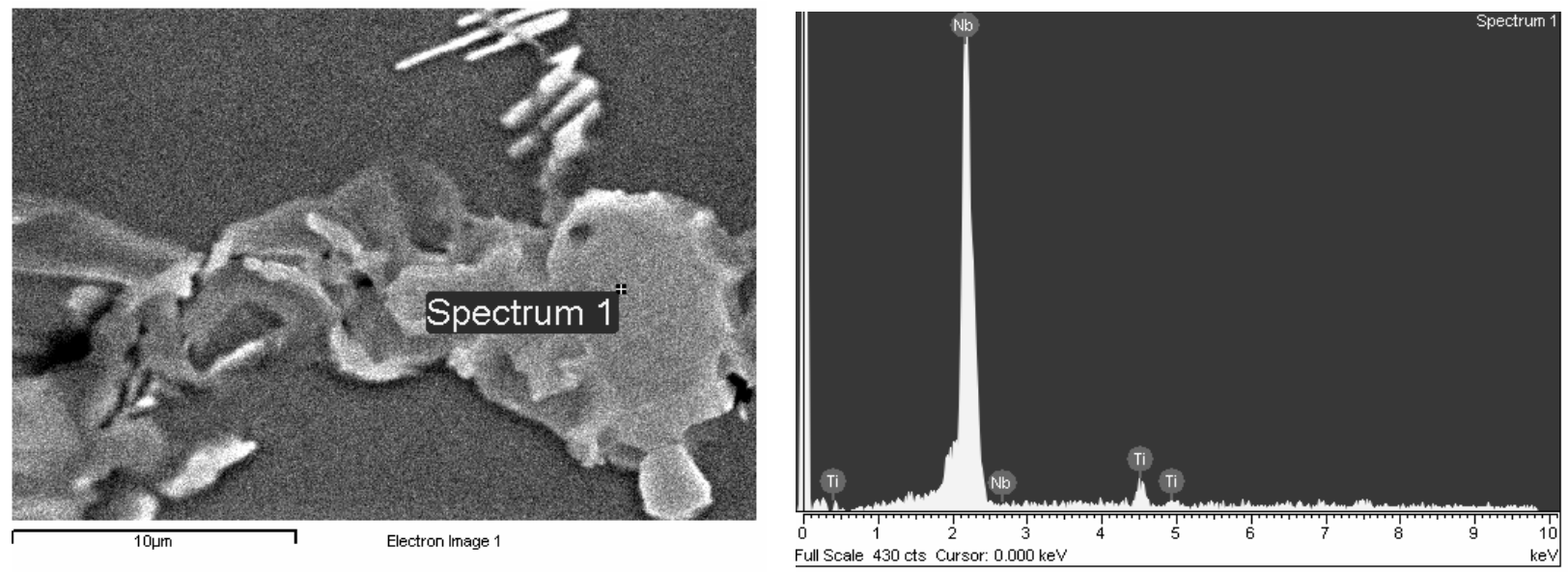

Fig. 9(a). Liquated MC carbide and (b) its EDS spectrum
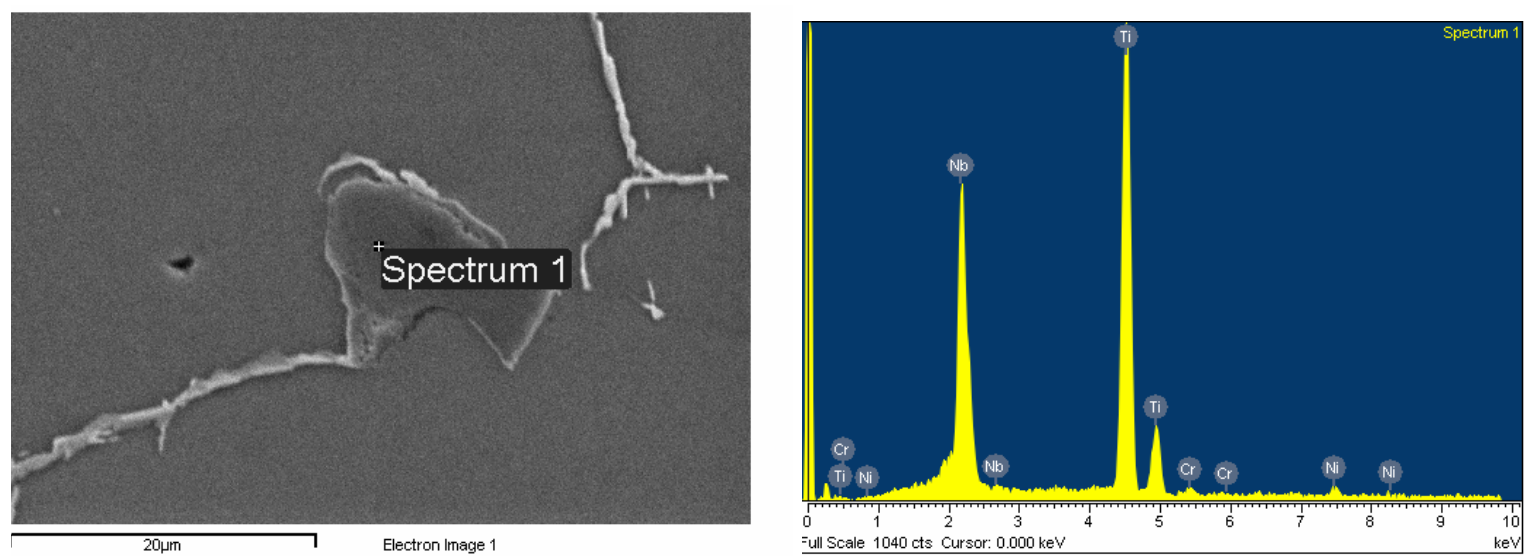

Fig. 10a. Liquated MC type Nb-Ti carbonitride and(b) its EDS spectrum.

The micro-fissured grain boundaries in the samples welded after the $1050^{\circ} \mathrm{C}$ heat-treatment were observed to have similar re-solidified products on them. The major difference between the microstructure of welds in the $950^{\circ} \mathrm{C}$ heat treated samples and that of the $1050^{\circ} \mathrm{C}$ heat treated samples was the absence of $\delta$ phase at the grain boundaries of the latter, as there was no $\delta$ phase present on them prior to welding. In other respects the compositions of the liquated and resolidified products were similar in the weld samples of all the three alloys that were given the two pre-weld heat treatments.

\section{Discussion}

As was described in the previous section, all the three alloys were given the same two pre-weld heat treatments and were welded using the same welding parameters. Welds in all the three alloys after both the pre-weld heat treated condition exhibited intergranular heat affected zone cracking. It should be noted that cracking did not occur in weld metal, although the porosity, often present at the bottom of the nail-shaped weld, had cracks associated with it. The extent of HAZ cracking was, however, different in the three alloys. Also, an increase in the pre-weld heat treatment temperature increased the degree of HAZ cracking in the same alloy.

It was observed that the HAZ microfissuring was almost always associated with resolidified products on the fissured grain boundaries. That is, the microfissuring of grain boundaries was 
due to "liquation cracking". Liquation cracking in Ni superalloys has been attributed to two main causes, viz., 1) suppression of melting point of grain boundary material by the segregation of $\mathrm{B}$ on them [6-10], and by the constitutional liquation of $\mathrm{NbC}$ particles $[2,4]$. Since one of the factors that governs the formation of various type of phases, including those that liquate, is dependent upon the composition of the alloy, liquation cracking should alsol be dependent upon the chemistry of the base material. Also, cracking of liquated regions of the material can only occur in the presence of tensile stresses. Therefore, the degree of cracking will also be influenced by welding and other tensile stresses during cooling of the welds.

The composition of the alloy differed significantly in terms of concentration of Ti, Al, B and $\mathrm{P}$, but the concentration of $\mathrm{Nb}$ and $\mathrm{C}$ was almost identical. The increase in the concentration of $\mathrm{Ti}$ and $\mathrm{Al}$ and a decrease in the concentration of Fe in 718 Plus as compared to Inconel 718 caused a change in the main strengthening phase from BCT- $\gamma^{\prime \prime}$ phase in Inconel 718 to $\gamma^{\prime}$ in 718 Plus alloy. It was reported earlier that an increase in the concentration of $\mathrm{Ti}$ and $\mathrm{Al}$ increases the hardness of the alloy as well as the hardness of the weld-metal because of the increased rate of precipitation and volume fraction of $\gamma^{\prime}$ phase during cooling of the weld, which has an adverse effect on HAZ cracking [11,12]. The difference in the weld-metal hardness would also be different between Inconel 718 and 718 Plus alloys because the rate of precipitation of $\gamma^{\prime \prime}$ phase is slower than that of $\gamma^{\prime}[11]$. Therefore, when the pre-weld heat treatment temperature is the same, (1) segregation of B at the grain boundaries would be the same in Inconel 718 and 718 Plus alloys HC 20 -, but may be greater in HC 49 because of its higher B concentration (2) the amount of $\mathrm{NbC}$ at the grain boundaries would also be the same in these three alloys. That is, the extent of liquation of grain boundaries in the Inconel 718 and HC 20-718 Plus specimens given the same pre-weld heat treatment temperature would also be identical, but would be greater in $\mathrm{HC}$ 49-718 Plus. However, hardness of pre-weld heat treated Inconel 718 alloy is significantly smaller as compared to that of 718 Plus. Therefore a portion of the welding and $\gamma^{\prime}$ precipitation stresses can be accommodated by the more ductile matrix of Inconel 718 superalloy, which would result in a reduced cracking of liquated boundaries.

The increased HAZ microfissuring in higher B and P 718 Plus alloy, HC 49, can be attributed to the increased segregation of $B$, as was observed in earlier studies on Inconel 718 [6, 8]. It was observed that the increased non-equilibrium segregation of B depressed the melting point of the grain boundary material which increased the temperature range over which the B segregated grain boundaries remained liquated. This made them more susceptible to intergranular cracking, as was observed in HC 49 version of 718 Plus superalloy as compared to HC 20 version with a lower concentration of B and P. That is, the liquation cracking in higher B and P alloy HC 49, should be the highest as compared to the other two alloys, as was observed.

It was also observed that in a given alloy an increase in the pre-weld heat temperature caused a very significant increase in the HAZ liquation microfissuring. This can be attributed to two effects due to an increase in the pre-weld heat treatment temperature: (1) increase in nonequilibrium segregation of B at grain boundaries, (2) increase in grain size.

It has been observed that an increase in the pre-weld solution treatment temperature increases the non-equilibrium segregation of $\mathrm{B}$ on grain boundaries due to an increase in the vacancy concentration, thus making them more susceptible liquation cracking [7, 10], as was observed in the present investigation. The effect of increase in the pre-weld solution treatment temperature would be even greater in higher B concentration alloy, $\mathrm{HC} 49$, as was also observed. 


\section{Conclusions}

1. Intergranular liquation microfissuring was observed in the heat affected zone of electron beam welded Inconel 718 and Allvac 718 Plus alloys.

2. The liquated and resolidified products at the cracked grain boundaries were identified to be laves $+\gamma$ eutectic, laves phase, liquated MC type carbides and Ti rich carbonitrides.

3. Compared to the conventional 718, 718 Plus alloys were observed to be more susceptible to HAZ microfissuring.

4. Amongst the 718 Plus alloys, the version with higher B and P showed more cracking than the version with normal $\mathrm{B}$ and $\mathrm{P}$.

5. Cracking in all the alloys increased with the increase in the pre-weld heat treatment temperature. This is attributed to the increase in non-equilibrium segregation of $\mathrm{B}$ and increased grain size.

\section{Acknowledgement}

The authors would like to thank ALLVAC for providing the alloys and Dr. Cao and Dr. Kennedy for many useful discussions. Thanks are also due to Natural Science and Engineering Research Council for the financial support.

\section{References}

1. W.A. Owczarski, D.S. Duvall, C.P. Sullivan, "A model of HAZ cracking in Nickel-base superalloys, Welding Journal, 54 (4), (1966), 145-s-155s.

2. R.G. Thompson, J.R. Dobss, D.E. Mayo, "The effect of heat treatment on microfissuring in Alloy 718, Welding Journal, 65 (11) (1986), 299-s-304s.

3. W.D. Cao, R. Kennedy, "Role of chemistry in 718 - type alloys - Allvac 718 Plus ${ }^{\mathrm{TM}}$ alloy development”, Superalloys 2004, ed. Green, K.A., Pollock, T.M., Harada, H., (TMS, 2004), 91-99.

4. R.G. Thompson, B. Radhakrishnan, D.E. Mayo, "Intergranular liquid formation distribution and cracking in the HAZ of Alloy 718 welds", Superalloy 718, ed., E.A., Loria, (1989), 437455.

5. M. Qian, J.C. Lippold, "The effect of annealing twin - generated special grain boundaries on HAZ liquation cracking of nickel - base superalloys", Acta Materialia, 51 (12) (2003), 33513361.

6. X. Huang, N.L. Richards and M.C. Chaturvedi, "The effect of grain boundary segregation of boron in cast Alloy 718 on HAZ microfissuring - a SIMS analysis", Acta Materialia, 45 (8) (1998), 3095-3107.

7. S. Benhadad, N.L. Richards and M.C. Chaturvedi, "The influence of minor elements on the weldability of an Inconel 718 - type superalloy", Metallurgical and Materials Transactions A, 33A (7) (2002), 2005-17.

8. H. Guo, M.C. Chaturvedi and N.L. Richards, "The effect of boron concentration and grain size on weld HAZ microfissuring in Inconel 718 base superalloys", Science and Technology of Welding and Joining, 4 (4) (1999), 257-264.

9. M.C. Chaturvedi, W. Chen, A. Saranchuk and N.L. Richards, "The effect of B segregation on heat-affected zone micro-fissuring in EB welded Inconel 718”, Superalloys 718, 625, 706 and Various Derivatives, ed. E.A. Loria, (The Minerals, Metals and Materials Society, 1997), 743-751. 
10. Huang, N.L. Richards and M.C. Chaturvedi, "Effect of homogenization heat treatment on the microstructure and heat-affected zone microfissuring in welded cast Alloy 718", Metallurgical and Materials Transactions A, 27A (3) (1996), 785-790.

11. K. Banerjee, N.L. Richards and M.C. Chaturvedi, "Effect of filler alloys on HAZ cracking in pre-weld heat treated IN-738LC GTA welds", Metallurgical and Materials Transactions A, (in press).

12. R.K. Sidhu, N.L. Richards and M.C. Chaturvedi, "Effect of aluminum concentration in filler alloys on HAZ cracking in TIG welded cast Inconel 738LC superalloy", Materials Science and Technology, (in press).

13. X. Huang, N.L. Richards and M.C. Chaturvedi, "Effect of grain size on weldability of cast alloy 718”, Materials and Manufacturing Processes, 19 (2) (2004), 285-311. 